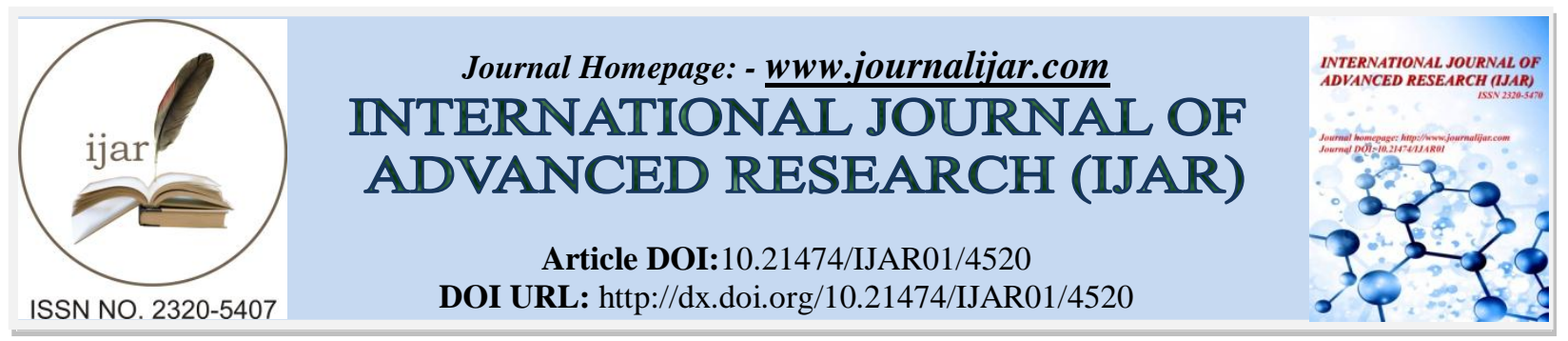

RESEARCH ARTICLE

\title{
ETHNOBOTANICAL STUDY OF THREE MEDICINAL AND AROMATIC SPECIES: SATUREJA NEPETA, MYRTUS COMMUNIS AND PISTACIA LENTISCUSFROM MASMOUDA TOWN (OUAZZANE PROVINCE: MOROCCO).
}

\author{
${ }^{*}$ Hayani Mouhcine ${ }^{1}$, Soro Kanigui N.T. Aminata ${ }^{1}$, Khiya Zakaria ${ }^{1}$, Rarchouf Samira ${ }^{1}$, Bruno Eto ${ }^{2}$, Sekkat \\ Chakib $^{1}$, Haloui Zoubida ${ }^{1}$ Oulhaj Hamid ${ }^{1}$ And Zair Touriya ${ }^{1,2}$. \\ 1. Research team of Chemistry bioactive moleculesand the environment, University Moulay Ismail, Faculty of \\ Sciences, BP 11201. Zitoune, Meknès, Morocco. \\ 2. Laboratory Trans Cell Lab, Faculty of Medicine Xavier Bichat 16, rue Henri Huchard, BP 416, 75870 Paris.
}

\section{Manuscript Info}

Manuscript History

Received: 18 April 2017

Final Accepted: 20 May 2017

Published: June 2017

\section{Key words:-}

Ethnobotanical study - Aromatic and medicinal plants - Satureja nepeta, Myrtus communis, Pistacia lentiscus Masmouda, Ouazzane.

\section{Abstract}

An ethnobotanical study of aromatic and medicinal plants was carried out in Masmouda mountainous area (Ouazzane province).

The aim of this study was to identify therapeutic usages of the most used species of this region. After confrontation of collected data by interviewing local people, syntheses allowed us to exploit this popular know-how. Then, monography of three selected species, namely Satureja nepeta, Myrtus communis and Pistacia lentiscus, was established as a contribution to save this orally transmitted knowledge. Based on testimony of 100 interviewees, this survey revealed that medicinal and aromatic plants (MAP) are used by $91 \%$ of the interviewees among them illiterate people $(70 \%)$ were the most depicted. It also revealed that these plants are most of the time used by men $(52 \%)$ older than 50.

According to the majority of interviewees, plants leaves are the most used organ and decoction is the preparation way generally used.

The study also showed importance of phytotherapy to Masmouda's people. This population exploits the three species for many therapeutic purposes in the following order: Satureja nepeta is the most used (75 $\%)$ then, follows Myrtus communis (58 \%) and Pistacia lentiscus ranks third (48\%).

Results provided by this study constitute a data basis for our further researches in phytochemistry and pharmacology with the aim to discover new bioactive and natural substances. Valorization of these results through pharmacology and industrial fields could ensure improvement of traditional medicine to a modern one and a renovated pharmacopeia.

Copy Right, IJAR, 2017,. All rights reserved.

\section{Introduction:-}

World vegetation forms various landscapes (forests, savannah, bushes, steppes etc.) that are rich in spontaneous plants species. For centuries, our ancestors used to relieve their pains and treat themselves with plants. Their 
medicinal experiences were kept and transmitted from a generation to another [1]. Nowadays, aromatic and medicinal plants remain the basis of alternative medicinal cares despite progression observed in modern health systems [2]. In developing countries, they constitute the main source of medication when modern medicine is not found [3] [4]. Thus, WHO (World Health Organization) showed its importance and recommended its integration into official health systems especially in developing countries [6].

Among 500000 vegetal species recorded on earth, 80000 are described as medicinal ones [5]. Morocco, as a phytogenetic tank formed with about 4500 vascular species and sub-species, is among mediterranean countries where inhabitants developed a real know- how in the field of medicinal plants [7]. However, bibliographic studies on this rich Moroccan flora showed that regional medicinal plants are scattered. Moreover, this know-how is now kept only by few people [8].In fact, transformation of this traditional knowledge into a scientific one is an important mean of revalorization and conservation that can lead to a rational use [9].

Therefore, this research, as others in floristic and ecological fields, has the same objectives as programs of international organisations such as World Union for Nature which aim is to promote sustainable uses of natural resources in North Africa and biodiversity conservation with involvement of local communities [10].

Thus, this study performed in Masmouda is a contribution to conservation of this traditional knowledge. It focuses on therapeutic uses of three medicinal and aromatic plants: Satureja nepeta=Menth, Myrtus communis=Rayhanand Pistacia lentiscus $=$ Drou[11].

\section{Material and Methods:-}

\section{Geographical and socio-economic frame of the target area:-}

Ouazzane is a town located in Moroccan North-west (Latitude: $34^{\circ} 48^{\prime} 36^{\prime \prime} \mathrm{N}$ and Longitude: $54^{\circ} 43^{\prime} 48^{\prime \prime} \mathrm{W}$ ). The town is found between pre-Rif hills and "Gharb" agricultural plain. Bordered in south-West by Loukous river, Ouazzane region covers about 616000 ha with 338000 ha dedicated to agriculture [12] [13]. The town belongs to Morocco southern zone called "Jbala country". Ouazzane territory is composed of different zones that are Masmouda, Rhouna, Ghzaoua and Beni Mestara. Latest population's census showed 307083 inhabitants with 165 inhabitants $/ \mathrm{Km}^{2}$ as a density (2008).

Administratively, Ouazzane belongs to the region called Gharb-Chrarda-Beni Hssen.

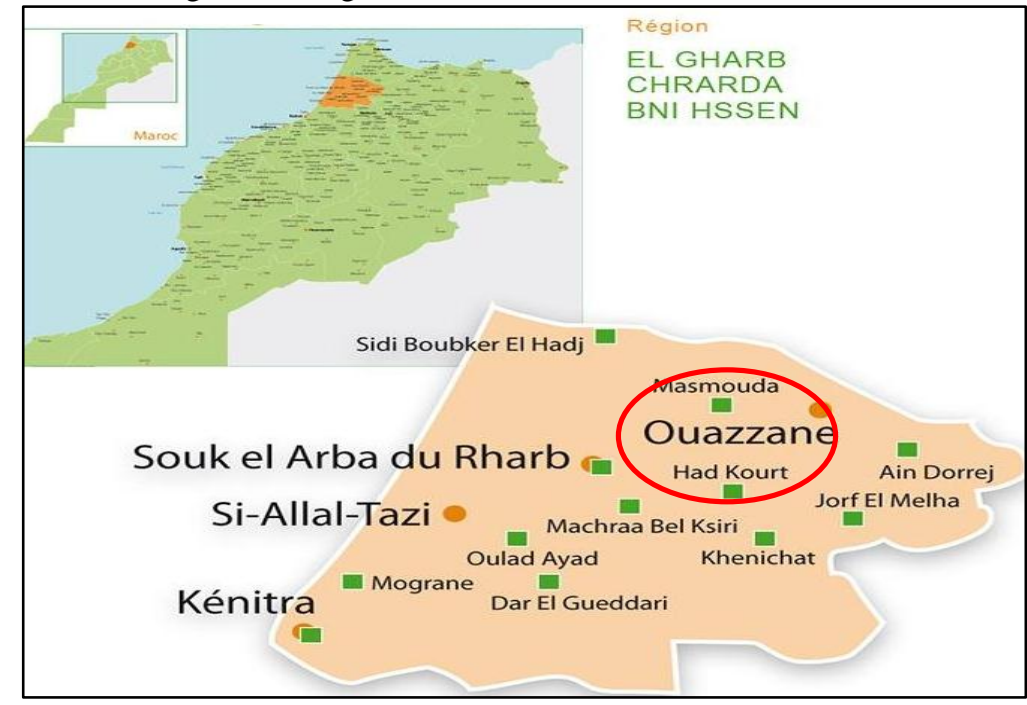

Figure 1:- Geographical maps of Ouazzane and Masmouda.

\section{Method of study:-}

Ethnobotanical study of AMP from Masmouda was realised based on a questionnaire in order to identify local and traditional usages of the selected plants [14] [15]. 
First, the survey helped us to gather information about informers: age, sex, level of study, occupation. Then, we focused our research on traditional usages of frequently used medicinal plants. For this work, we chose three species: Satureja nepeta (Menth), Myrtus communis (Rayhan)and (Pistacia lentiscus=Drou) based on a pre-survey carried out in Masmouda region.

\section{Method of data Gathering:-}

Data gathering on AMP required 100 questionnaires filled in by Masmouda's people within 17days of March 2014. Each plant's potentialities were evaluated thanks to this questionnaire that helped us to identify several usages [16]. The questionnaire drew an exhaustive list of all aspects to raise. The interviewees were targeted in order to include local people and all actors interested in traditional medicine.

In practice, the study consisted into two steps. The first one was related to the questionnaire to fill in by all actors of the sector (herb-sellers, traditional doctor, inhabitants) and the second one was an exploration and recognition phase on the spot (in Masmouda's markets, with herb-sellers, traditional doctor,... ). Then, data were analysed by SPSS 16 software.

\section{Results and Discussion:-}

Results are classified according to therapeutic practices, plants uses and diseases. All results are graphically presented.

\section{The use of AMP in Masmouda Region:-}

Masmouda inhabitants use plants as the principal source of therapy and consider it as a good alternative of modern medicine. The following diagram shows that $92 \%$ of Masmouda inhabitants use aromatic and medicinal plants in their daily life.

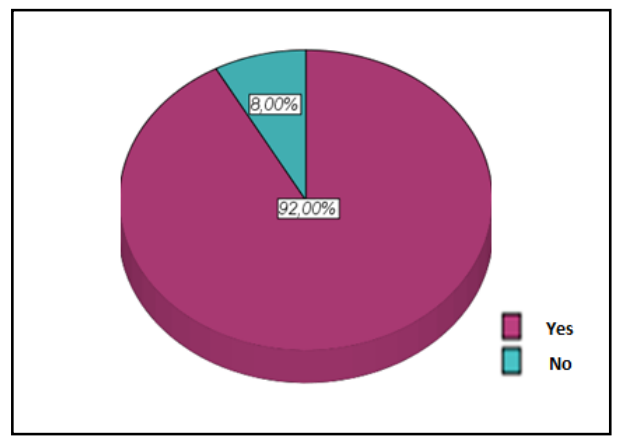

Figure 2:- The use of AMP in study's region.

Despite the growing influence of the modern health system, plants continue to respond to the need of many populations who use it to insure health care. The medicinal plants and medicine derived from plants are considered to be a soft and less toxic source of remedy comparing to conventional medicine; hence, populations keep using it on a national and international level, as many authors reported in their studies [17] [18][19] [20] [21].

\section{Origin of AMP in study's region:-}

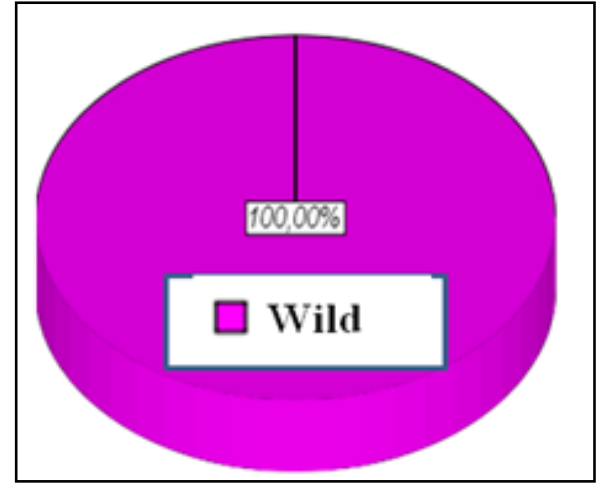

Figure 3:-Origin of AMP in Masmouda's region. 
The 17-days survey in Masmouda revealed that target AMP (Satureja nepeta, Myrtus communis and Pistacia lentiscus)used by people are all from a wild origin (Figure 3). This information is coherent with assertion of R. Rhafouri et al., (2014)[22].

\section{Frequency of AMP use according to the Gender:-}

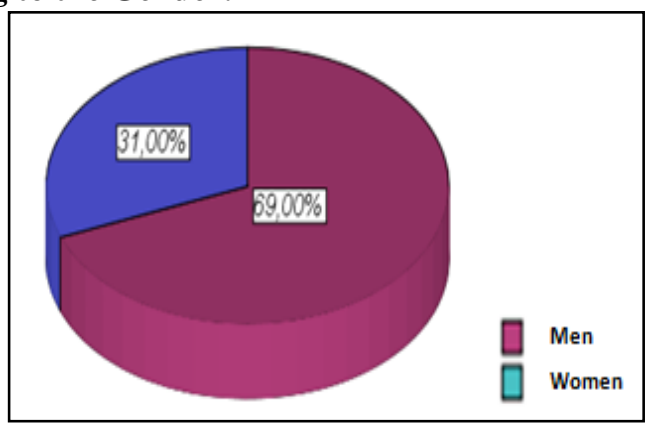

Figure 4:- Frequency of AMP use according to the gender .

Results depicted in figure 4, showed that men (69\%) are more knowledgeable than women (31\%) about traditional phytotherapy. Men are used to collect medicinal plants from dangerous places therefore they benefit from these plants to relieve pain and remain healthy. This observation has also been made at a national scale by other authors in their ethnobotanical studies [22].

However, it is not always the case in Morocco. Other studies such as those of Benkhnigue et al., (2011) [9] are in contrast with ours. In their studies done on a national level, these authors note that women are more knowledgeable of traditional phytotherapy comparing to men.

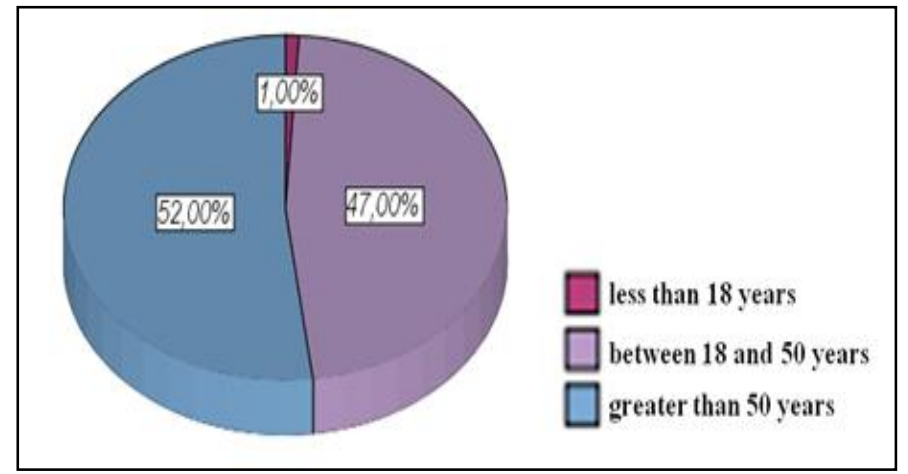

Figure 5:- Frequency of AMP use according to the age.

In the target region, use of AMP is widespread into two age clusters (figure 5). The most frequent users are the old (older than 50) (52\%). They are followed by people between 18 and 50 years old (47\%). Very young people do not have great interest in this matter: only $1 \%$ of the users of AMP are younger than 18.

This distribution symbolizes transmission of this empirical traditional knowledge from the old to the youth. Results analysis shows that both the youth and the older from Masmouda give importance and show great interest in aromatic and medicinal plants. 


\section{Informers' Occupation:-}

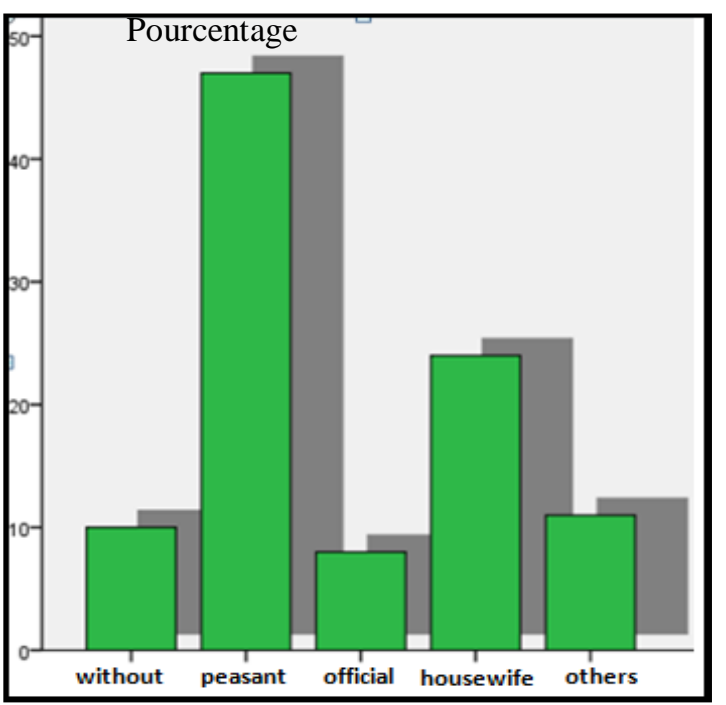

Figure 6:- Informers' occupation in Masmouda region.

In our survey, we notice that $47 \%$ of the informers are peasant. Housewives also (24 \%) do have a relevant knowledge. People with liberal occupations (10\%), people without any job (10\%) as well as officials $(8 \%)$ are also interested in AMP (figure 6).

These results are similar with those of Polat et al., (2015) [23] who found during their investigation that all women are housewives and most of men are farmers.

Frequency of AMP use according to the level of study:-

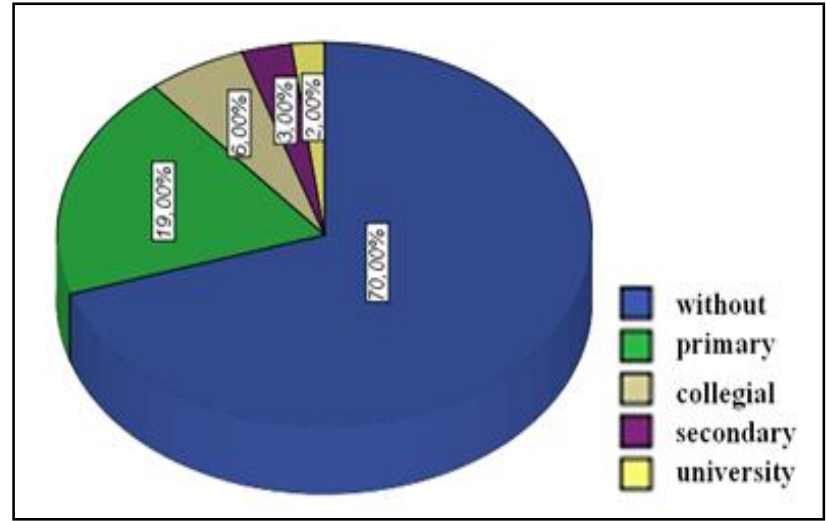

Figure 7:-Frequency of AMP use according to the level of study.

In Masmouda, most of people using medicinal plants are illiterate (70\%). Nevertheless, people with primary school level depict a significant percentage (19\%). 6\% and 3\% of medicinal plants users are people with respectively lower and upper secondary school level while People with university level rarely use AMP. Only 2\% of AMP's users reached this academic level.

This is related to the rate of illiteracy which is generaly high in the region and in general in the rural areas. Also, the lack of public transportation, the isolation of the region and the lack of infrastructures, especially educational level that contribute definitely to the high rates of illiteracy also the rate of school dropout illustrated in the figure 7 .

Also, people of rural areas who want to persue their studies, are obliged to leave their areas (rich of medicinal plants) for the urban area which is more sophisticated, more developed and far from nature. This is why rural areas 
suffer the brain drain. Because, for those who went from rural to urban areas, a new life style is installed hence, manners including plants treatment disappear.

On the other hand, the knowledge in term of phytotherapy continue to be a "proprety" of healers and elderly persons who for national condition are the most illiterate people as farmers and housewives especially in rural areas. The reason why our investigation highlights a concordance between the level of study, the profession and the age of informants.

Finally, the absence of education in this science which is traditional use of plants in schools and universities explains the few people who have knowledge in this field. That's why it is the opportunity to suggest initiatives which include a set of advantages especially for the conservation of this heritage.

Frequency of plants' use:-

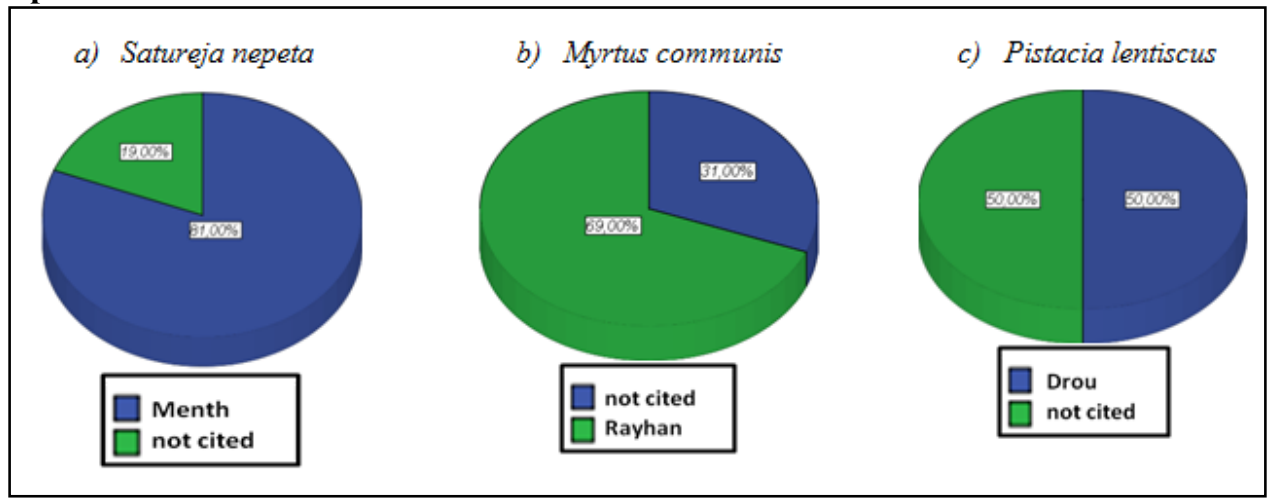

Figure 8:- Frequency of plant use.

Figure 8 shows frequencies of usage of Satureja nepeta (Menth), Myrtus communis (Rayhan) and Pistacia lentiscus (Drou).

The survey highlighted the fact that among the three target species, Satureja nepeta (Menth) is the most popular: $81 \%$ of the interviewees do have information about it while $19 \%$ don't have any information about the species. Then, Myrtus communis (Rayhan) follows: 69\% keep information about its presence in the region and 31\% don't. Finally, Pistacia lentiscus (Drou) has the third rank with 50\% of people who know its usages and 50\% who never heard about it.

Popularity of Satureja nepeta might be due to its therapeutic virtues as well as its abundance in this region.

Hence, the results show that Satureja nepeta et Myrtus communis are very used by inhabitants of Masmouda region. The findings highlight not only the abundance of these plants in the region but also their therapeutic benifits. This is suggested by other studies such as those of Tahri et al., (2012) in Settat (Morocco) and Orch et al., (2015)in the region of Izarène (north of Morocco) [17] [18] which show the presence of these plants in other regions of the country and the interest of local population in the frequent use of these medicinal plants. 


\section{Plants Usages:-}

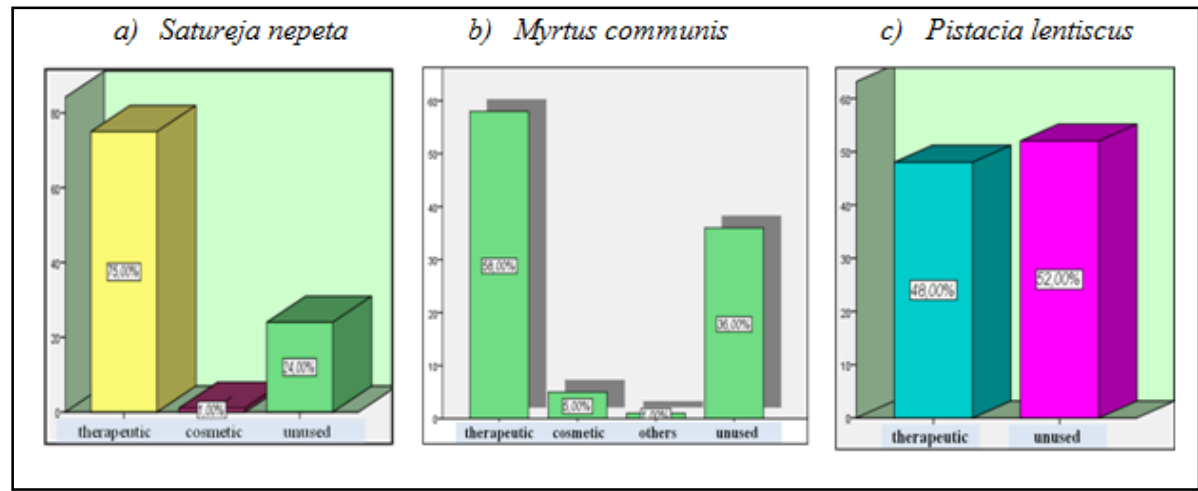

Figure 9: Plants usages.

Genarally, in Masmouda region, Satureja nepeta is the most used species. $76 \%$ people do use it for various needs while the other species (Myrtus communis and Pistacia lentiscus) are less common. Both species are not used by relatively high number of person: respectively $36 \%$ and $52 \%$ of interviewees don't use Myrtus communis andPistacia lentiscus (figure 9) even if part of them knows traditional practices about the species. Besides, we see that users generally resorted to these plants for therapeutic purposes. Satureja nepeta is used fortherapeutic reasons with a frequency of $75 \%$ and the two others Myrtus communis andPistacia lentiscus are used respectively with 58 $\%$ et $48 \%$ for the same objective. Satureja nepeta and Myrtus communis are sometimes (1\% and $5 \%$ respectively) used by people for cosmetic purposes while Pistacia lentiscus is exclusively used for its therapeutic virtues. The ethnobotanical studies of Orch and al., (2015) [18] and Tahri et al., (2012) [17] demonstrate the therapeutic use of genres studied in other regions of Morocco. Various studies on biological activities have shown that genres (grouping these species) possess antibacterial, antifungal and antioxidant activities [24] [25] [26] which explains their uses by the population.

\section{Plants' Organs:-}



Figure 10:-frequency of used organs .

In traditional medicine, several organs can be used to benefit from plants virtues. These organs might be: stems, flowers, roots, leaves or even the whole plant. In our case, leaves are the main organs used for all the plant species (figure 10). Sometimes, the whole plant might be used.This is the case for all plants: Satureja nepeta (20\%), Myrtus communis $(10 \%)$ and Pistacia lentiscus $(5 \%)$. On the other hand, stems and flowers of the three species are rarely used and roots are not used by Masmouda's people.

\section{Mode of preparation:-}

People from Masmouda use different ways for plants preparation. In order to administer active principles, they prepare decoction, infusion or powder from plants. They sometimes use the plants as raw material as well as cooked material or cataplasm. In this survey, decoction was clearly identified as the major practice for all the three plants. Recorded frequencies of decoction were respectively $42 \%$ for Satureja nepeta, $48 \%$ for Myrtus communis and $31 \%$ for Pistacia lentiscus (figure 11). 
Infusion mode is often used to administer the plants' substances and this is particularly the case for Satureja nepeta (27\%). Dried-plant powder is rarely used: this process is about 3 to $5 \%$ as usage frequency. Other preparation modes like fumigation, cataplasm, etc. are less used. Our results are similar with those of Polat et al., (2015) [23] who suggests that population prefer the use of simple methods of preparation such as decoction and infusion. It's affordable and inexpensive preparation method, and too much easy. Given that the population concerned with medicinal plants in rural areas (such as Masmouda) is generally relatively modest to poor (peasants, housewives, etc.), the choice of these methods of preparation is quite Strategic and coherent. Because health is a necessity for all people regardless of the standard of living, these means enable even the poorest to access health care in the event of illness.

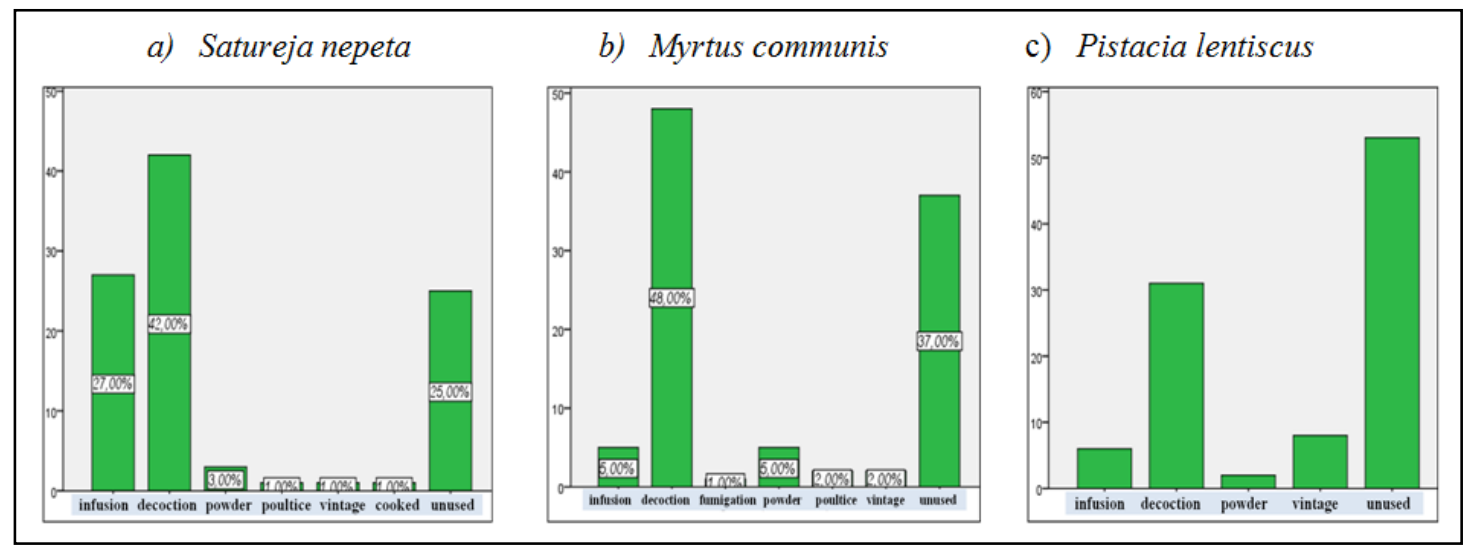

Figure 11:- preparation mode of AMP.

\section{Ailments:-}

Satureja nepeta, Myrtus communis and Pistacia lentiscus are used in the region to treat a great number of ailments. They are generally used to relieve or treat diseases related to respiratory, digestive or uro-genital tract. They are also useful to treat skin diseases and osteoarticular disorders. The picture below (figure 12) summarizes the collected data. Respiratory ailments are the main reasons for usageof Satureja nepeta (56\%) and Myrtus communis (28\%) while Pistacia lentiscus is used to treat digestive diseases (36\%). According to collected data, Myrtus communis seems to treat a diversity of illnesses: skin ailments (8\%), osteoarticular disorders (9\%), digestive diseases (16\%), respiratory ailments (28\%) whereas Satureja nepata and Pistacia lentiscus seem to be more specialize either for respiratory diseases or digestive ones. The method of preparation used by the population regardless of its simplicity, allow the extraction of active substances and molecules that helps the users to fight against different pathologies. These results show the efficiency of plants for treating many infection which explains their use by the global population [20][16][17][27][21].
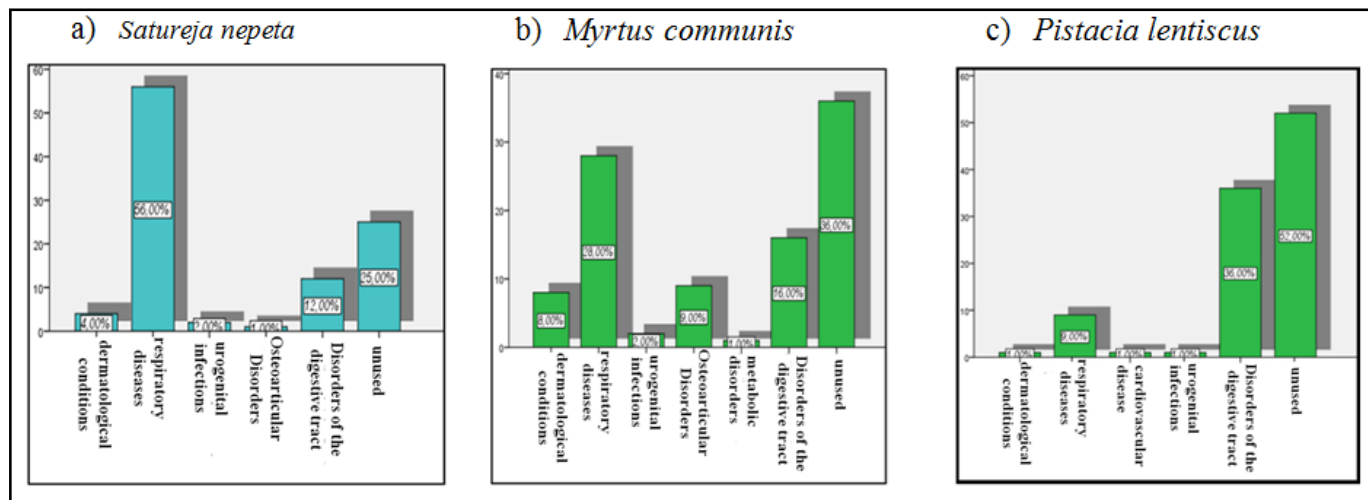

Figure 12:- ailments treated by the selected plants.

\section{Dosage:-}

In the target region, people do not use aromatic and medicinal plants with precise dosage. Dose measurements differ from one person to another. Globally, measures can be a pinch, a handful or anything else. Generally, people do use an arbitrary amount of plant. This attitude was illustrated by high frequencies registered during the survey. For 
satureja nepeta, $48 \%$ of users do not have an exact idea about the plant amount needed for administration. This frequency is $45 \%$ forMyrtus communis and $39 \%$ for people who use Pistacia lentiscus.

When the amount of plant is approximately assessed, people generally use a handful of plant. It is exactly the case for all the three plant with relatively significant frequencies: Satureja nepeta $26 \%$, Myrtus communis $18 \%$ and Pistacia lentiscus $8 \%$. For all the plants, pinch is rarely used. Its usage frequency is $1 \%$ for all the three species. From these figures, we notice that people do not pay a great attention to dosage when healing with medicinal plants. They use various quantities and do not care about a precise amount of plant to administer. This behaviour may be dangerous since it may lead to intoxication cases.

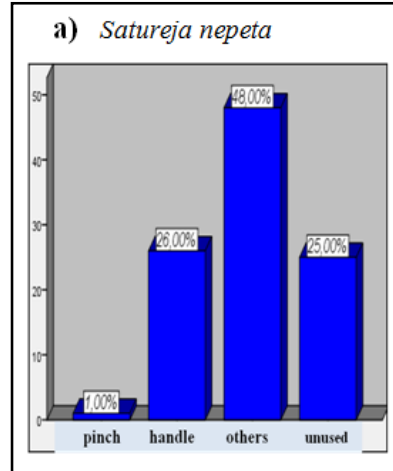

Administration mode:-

Many ways of administration has been used by Masmouda's people. They are namely:-

oral route, skin route especially by massage, rinsing and painting (figure 14). Based on the results of our survey, we can affirm that all plants are essentially orally administered. For this administration route, frequencies are: $72 \%$ for Satureja nepeta , 57\% for Myrtus communis and 46\% for Pistacia lentiscus. Rinsing and painting are rarely used by people. Massage, painting and rinsing modes have each a frequency of $1 \%$ for Satureja nepeta. For Myrtus communis painting frequency is 5\%. Massage mode reach only $2 \%$ for Pistacia lentiscus.

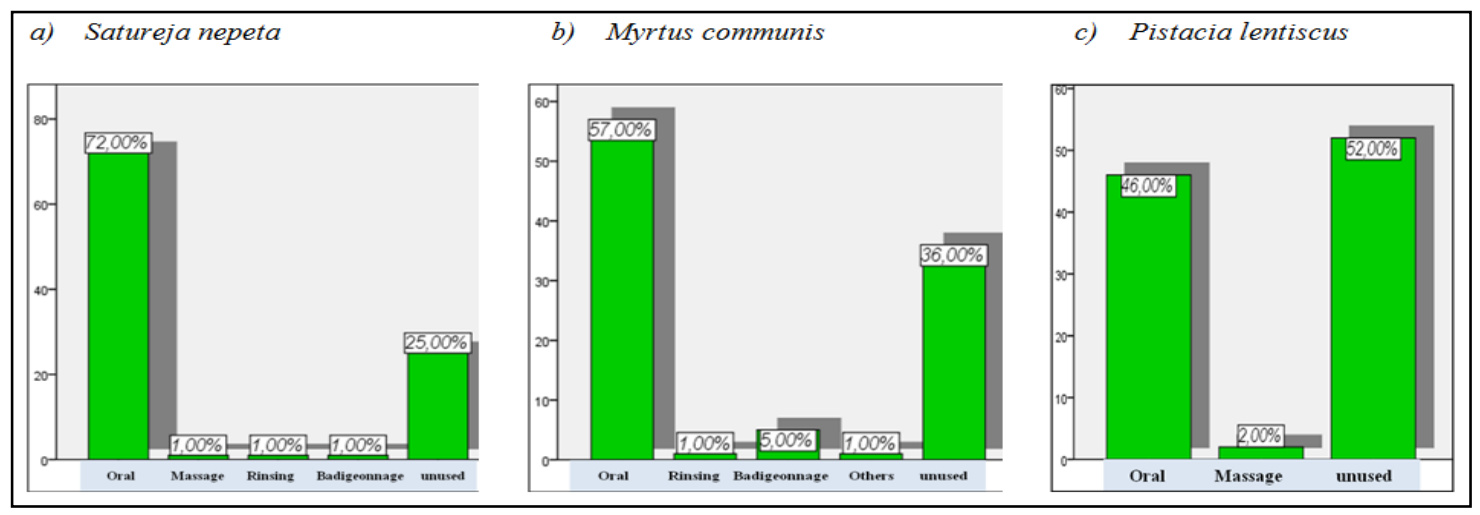

Figure 14:- Administration mode

Treatment length:-

The length of the treatment is variable. It could be from one day to several days. Generally, people administer the plant until recovery. This observation is made for all the plants. Considering absolute frequencies, $75 \%$ of people use Satureja nepeta until recorvery while $62 \%$ do the same for Myrtus communis and $47 \%$ uses Pistacia lentiscus until they recover (figure 15). These figures expressed as relative frequencies mean that all users of Satureja nepeta and Pistacia lentiscus choose to administer the plant until recovery. For Myrtus communis, only few people use the plant for one day, the others use the plant until recovery. 




Figure 15:- treatment length.

\section{Plants toxicity:-}

The survey shows that the selected plants are non-toxic for human beings. According to information collected from Masmouda's people, Satureja nepeta is declared non-toxic by all users since $75 \%$ of people use it while $25 \%$ of people don't. The same pattern is observed for both Myrtus communis and Pistatcia lentiscus. All users of these species meaning 64\% and $48 \%$ of the interviewees respectively for Myrtus communis and Pistacialentiscusagree about the non-toxic property of the species.

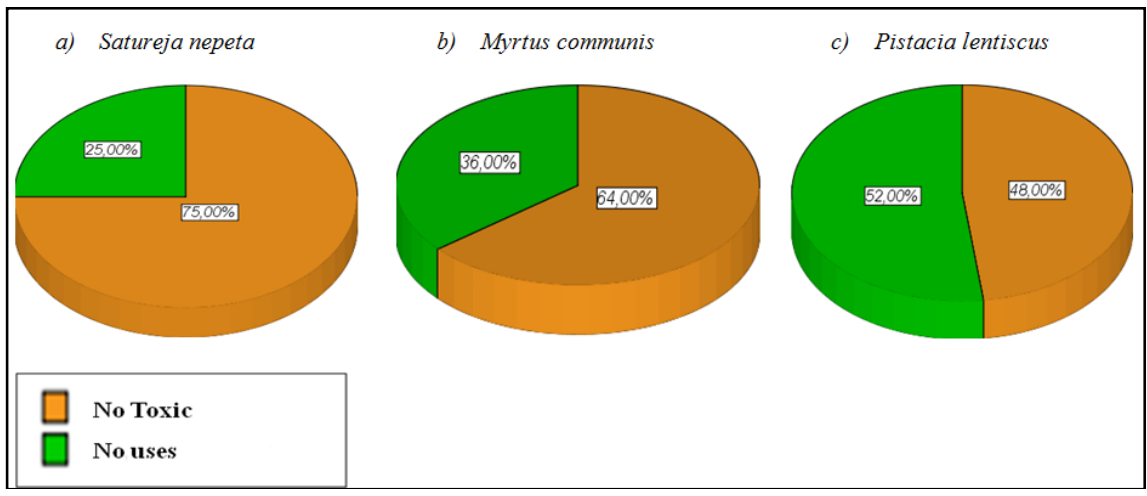

Figure 16:0-Plants toxicity.

\section{Treatment of Diseases:-}

In general, the treatment of diseases by aromatic and medicinal plants must be done through experiences and also through several stages. They are made by educated herbalists or pharmacists who are credited by the state (royal decree or ministerial). Our survey covers all categories of the population of the Masmouda area (Souk, educated and out-of-school herbalists, as well as the inhabitants of the mountain). The illiterate (70\%) and the educated (primary ... and academic) have shown their efficiencies in the use of medicinal aromatic plants (Pistacia lentiscus, Myrtus communis and Satureja nepeta, ..) in the wild as healing products against all diseases or Infections. The results obtained showed that $91 \%$ used by itself medicinal plants compared to $9 \%$ who did not use medicinal plants in the study area.

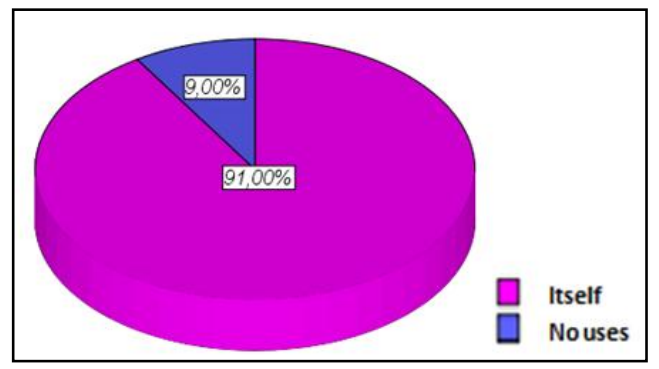

Figure17:-Diagnosis of the use of AMP.

\section{Treatments efficiency:-}

According to our survey on the aromatic and medicine plants studied (Satureja nepeta, Myrtus communis, Pistacia lentiscus) in the Masmouda area, we included that the plants when it used as a therapeutic substance showed 
efficacy [17] in diseases curing. The results of the study ( figure 18) show that 91\% of people from the population say that the use of the studied aromatic and medicine plants studied allows a cure of the diseases treated [19][23][21].

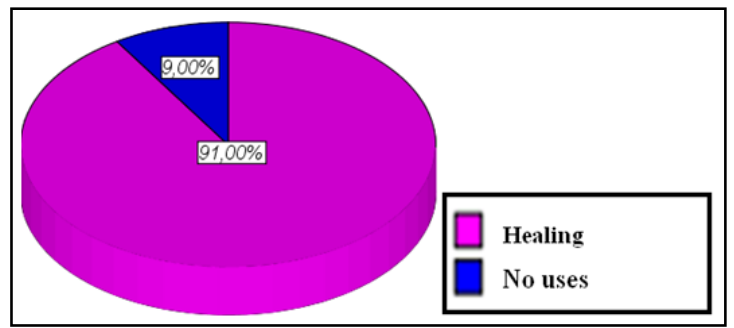

Figure 18:- treatment efficiency.

\section{Conclusion:-}

People of Masmouda have a strong link with medicinal plants. In our study, we showed that the three selected species are used as a source of therapeutics to treat various ailments. Abundance, efficiency and non-toxic property of these plants are surely the main reasons that justify their usage by local people. Through this survey, information collected about these three species could be considered as a contribution to valorize Masmouda's flora and to safeguard the local know-how.

\section{References:-}

1. B Yves-Alain; A Janat; B Mamyrbekova; B BOUA; H Trabi; E Éhilé.Étude ethnobotanique et screening phytochimique de Caesalpinia benthamiana(Baill.) Herend. et Zarucchi (Caesalpiniaceae), Sciences \& Nature, 2007, Vol. $4 \mathrm{~N}^{\circ} 2: 217-225$.

2. D Belghyti; M. Elqaj; A Ahami. La phytothérapie comme alternative à la résistance des parasites intestinaux aux antiparasitaires, Journée Scientifique « Ressources Naturelles et Antibiothérapie », 2007, Faculté des Sciences - Kénitra.

3. J.R.S Tabuti; K.A Lye; S Dhillion. Traditional herbal drugs of Bulamogi, Uganda: plants, use and administration. J. Ethnopharmacology, 2003, 88: 19-44.

4. T Jiofack; C Fokunang; N.M Guedje; E Fongnzossie; B.A Nkongmeneck; P.M Mapongmetsem; Tsabang. Ethnobotanical uses of medicinals plants of two ethnoecological regions of Cameroon. International Journal of Medicine and Medical Sciences, 2010, 2 (3): 60-79.

5. A Quyou. Mise au point d'une base de données sur les plantes médicinales. Thèse de Doct. Univ. Ibn Tofail. Fac. Sci. Kénitra, Maroc, 2003, 110 p.

6. E Flahaut. Pharmacopée et médecine traditionnelle dans l'ouest du Burkina Faso. Plantes médicinales et soins du couple mère-enfant. Thèse de Doctorat en Pharmacie, Université de Lille II, 1999, 143p.

7. A.M Scherrer; i R Mott; C.S. Weckerle. Traditional plant use in the areas of Monte Vesole and Ascea, Cilento National Park (Campania, Southern Italy). J. Ethnopharmacology, 2005, 97, 129-143.

8. H Zerkani; I Tagnaout; Zair T. Ethnobotanical survey and inventory of medicinal flora in the rural municipalities of Ait Ishaq, Tighassaline, El-Hammam and Ageulmam azegza - Khenifra province, MoroccoJournal of Chemical and Pharmaceutical Research, 2015, 7(8):611-627.

9. O Benkhnigue; L Zidane; M Fadli; H Elyacoub; A Rochdi; A Douira. . Etude ethnobotanique des plantes médicinales dans la région de Mechraâ Bel Ksiri(Région du Gharb du Maroc) Acta Bot. Barcelona, 2010, 53: 191-216,

10. A Kahouadji; S Hseini. Étude ethnobotanique de la flore médicinale dans la région de Rabat (Maroc occidental) LAZAROA 2007, 28: 79-93.

11. R. Mehdioui; A Kahouadji. Etude ethnobotanique auprès de la population riveraine de la forêt d'Amsittène: cas de la Commune d'Imi n'Tlit (Province d'Essaouira). Bulletin de l'Institut Scientifique, Rabat, section Sciences de la Vie 2007, 29: 11-20.

12. ORMVAG (Office régionale de la mise en valeur agricole). Monographie de Machraa Bel Ksiri. 2002,30 p.

13. Haut-commissariat au plan (H.C.P), Recensement général de la population et de l'habitat, Plan d'aménagement et de gestion du Parc d'Ifrane (rapport diagnostic, version finale), 2004, 65-74.

14. H Lahsissene; A Kahouadji; M Tijane; S Hseini. Catalogue des plantes médicinales utilisées dans la région de zaër (Maroc occidental).Lejeunia, 2009, BE ISSN 0457-4184.

15. N Benlamdini; M Elhafian; A Rochdi; L Zidane. Étude floristique et ethnobotanique de la flore médicinale du Haut Atlas oriental (Haute Moulouya), Journal of Applied Biosciences, 2014, 78:6771 - 6787. Kénitra, Maroc. 
16. S Salhi; M Fadli; L Zidane; A Douira. Etudes floristique et ethnobotanique des plantes médicinales de la ville de Kénitra (Maroc). Lazaroa, 2010, 31: 133-146.

17. N Tahri; A El basti; L Zidane; A Rochdi; A Douira. Etude Ethnobotanique Des Plantes Medicinales Dans La Province De Settat (Maroc), Journal of Forestry Faculty, 2012, 12 (2): 192-208.

18. H Orch; A Douira; L ZIDANE. Étude ethnobotanique des plantes médicinales utilisées dans le traitement du diabète, et des maladies cardiaques dans la région d'Izarène (Nord du Maroc), Journal of Applied Biosciences, 2015, 86:7940- 7956.

19. E.O. Omwenga; A.Hensel; A.Shitandi; F.M.Goycoolea. Ethnobotanical survey of traditionally used medicinal plants for infections of skin, gastrointestinal tract, urinary tract and the oral cavity in Borabu sub-county, Nyamira county, Kenya Journal of Ethnopharmacology, 2015, 176,508-514.

20. G.H Sam; F Adu; K Annan..Ethnobotanical survey of medicinal plants used for the treatment of diarrhea and skinulcerin the Brong Ahafo region of Ghana. J.Med.Plants, 2013, Res.7,3280-3284.

21. H Bhatia; Y.P Sharma; R.K Manhas; K Kumar.. Ethnomedicinal plants used by the villagers of district Udhampur, J\&K, India. Journal of Ethnopharmacology, 2014, 151, 1005-1018.

22. R Rhafouri; A Aafi; T Zair; B Strani; M El Omari; M. Ghanmi; A Bentayeb. Ethnobotanical study of medicinal plants in Ifran's National Park, Morocco, 2014.

23. R.Polat; UgurCakilcioglu; KaanKaltalioğlu; MusaDenizhanUlusan; Z Türkmen. An ethnobotanical study on medicinal plants in Espiye and its surrounding (Giresun-Turkey) Journal of Ethnopharmacology, 2015, 163,111.

24. W Aidi Wannes; B Mhamdi; J Sriti; M Ben Jemia; O Ouchikh; G Hamdaoui; M Elyes Kchouk; B Marzouk. Antioxidant activities of the essential oils and methanol extracts from myrtle (Myrtus communis var. italica L.) leaf, stem and flower, Food and Chemical Toxicology 48 (2010) 1362-1370.

25. N Bougandoura; N Bendimerad. Evaluation de l'activité antioxydante des extraits aqueux et méthanolique de Satureja calamintha ssp.Nepeta (L.) Briq. Laboratoire des Produits Naturels, Université Abou Bakr Belkaid, 2012, BP 119, Tlemcen 13000, Algérie.

26. G Chryssavgi; P Vassiliki; M Athanasios; T Kibouris; K Michael; Essential oil composition of Pistacia lentiscus L. and Myrtus communis L.: Evaluation of antioxidant capacity of methanolic extracts. Food Chemistry, 2008, 107 (2008) 1120-1130.

27. H Jouad; M Haloui; H Rhiouani; J El Hilaly; M Eddouks.. Ethnobotanical survey of medicinal plants used for the treatment of diabetes, cardiac and renal diseases in the North centre region of Morocco (Fez-Boulemane). Journal of Ethnopharmacology 2001, 77, 175-182. 